\title{
The occurrence of methicillin-resistant non-aureus staphylococci in samples from cows, young stock, and the environment on German dairy farms
}

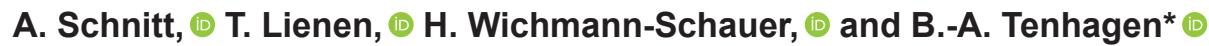 \\ Department of Biological Safety, German Federal Institute for Risk Assessment, 10589 Berlin, Germany
}

\begin{abstract}
This study aimed to determine the occurrence of methicillin-resistant (MR) non-aureus staphylococci (NAS) on 20 preselected German dairy farms. Farms were selected based on the detection of methicillin-resistant Staphylococcus aureus (MRSA) during previous diagnostic investigations. Bacterial culture of presumptive MR-NAS was based on a 2-step enrichment method that has been recommended for MRSA detection. Quarter milk samples (QMS), bulk tank milk, swab samples from young stock, and environmental samples were collected for bacterial culture. Methicillin-resistant NAS were detected on all study farms. The MR-NAS positive test rate was 3.3\% $(77 / 2,347)$ in QMS, $42.1 \%$ $(8 / 19)$ in bulk tank milk, $29.1 \%(59 / 203)$ in nasal swabs from milk-fed calves, $18.3 \%(35 / 191)$ in postweaning calves, and $7.3 \%(14 / 191)$ in nasal swabs from prefresh heifers. In the environment, MR-NAS were detected in dust samples on $25 \%(5 / 20)$ of the dairy farms as well as in teat liners and suckers from automatic calf feeders. The geometric mean somatic cell count in QMS affected by MR-NAS (183,000 cells/mL) was slightly higher compared with all QMS (114,000 cells/mL). Nine MR-NAS species were identified; Staph. sciuri, Staph. lentus, Staph. fleurettii, Staph. epidermidis, and Staph. haemolyticus were the most common species. In addition, 170 NAS isolates were identified that showed reduced cefoxitin susceptibility $(4 \mathrm{mg} / \mathrm{L})$ but did not harbor the mecA or mec $C$ genes. On some farms, similar mobile genetic elements were detected in MR-NAS and MRSA. It was suggested that resistance genes may be transferred between NAS and Staph. aureus on the respective farms.
\end{abstract}

Key words: methicillin, non-aureus staphylococci, coagulase-negative staphylococci, antimicrobial resistance, dairy cattle

Received September 28, 2020.

Accepted December 8, 2020.

*Corresponding author: Bernd-Alois.Tenhagen@bfr.bund.de

\section{INTRODUCTION}

Non-aureus staphylococci are a diverse group of bacteria that have been detected on dairy farms worldwide. Because most NAS species are coagulase negative, this group of bacteria was formerly referred to as "coagulasenegative staphylococci." In different studies about $8 \%$ of mastitis milk samples carried NAS (Ruegg, 2018). Although NAS have been regarded as minor mastitiscausing pathogens, the effect of NAS on udder health and milk quality was reported to be higher in heifers and in herds with overall good udder health (Schukken et al., 2009; Condas et al., 2017). The most frequently detected NAS species from mastitis milk samples of dairy cows are Staph. chromogenes, Staph. simulans, Staph. xylosus, Staph. haemolyticus, and Staph. epidermidis (Vanderhaeghen et al., 2015; Condas et al., 2017). Studies on epidemiology, host adaption, and pathogenicity of NAS provide evidence that NAS species can act as commensals, opportunistic and obligate pathogenic bacteria (Supré et al., 2011; De Visscher et al., 2014). Staphylococcus chromogenes especially seems to be host adapted and pathogenic, and other NAS species (e.g., Staph. haemolyticus, Staph. fleurettii, and Staph. equorum) should be regarded as opportunistic environmental pathogens (Vanderhaeghen et al., 2015; De Visscher et al., 2017; Jenkins et al., 2019).

Methicillin-resistant (MR) NAS are resistant to $\beta$-lactam antibiotics, which is the most important group of antibiotics approved for mastitis therapy in dairy cows. Broad-spectrum $\beta$-lactam resistance in staphylococci is often mediated by the mecA or mecC genes, which encode for the modified penicillin binding protein 2a and are well known from MR Staph. aureus (MRSA). The diversity of mecA genes is higher in NAS and MR-NAS compared with Staph. aureus and MRSA (Becker et al., 2014; Miragaia, 2018). In addition, MIC for phenotypic methicillin resistance testing using cefoxitin or oxacillin are highly heterogeneous (Dickinson and Archer, 2000). Therefore, the overall burden of MR-NAS is difficult to evaluate, and comparison between studies is challenging due to different sample types and detection methods. 
The most frequently detected MR-NAS species from mastitis in dairy cows are MR Staph. epidermidis (MRSE; Gindonis et al., 2013; Seixas et al., 2014; Nobrega et al., 2018) and MR Staph. sciuri (Cicconi-Hogan et al., 2014; Mahato et al., 2017; Fisher and Paterson, 2020). In hospitals, MRSE emerges as a major pathogen associated with immunocompromised patients and foreign body infections (Becker et al., 2020).

Numerous studies have reported methicillin resistance in NAS isolates from mastitis milk samples; however, little is known about the occurrence and distribution of MR-NAS in the different habitats on dairy cattle farms. Therefore, we aimed to determine the occurrence and genotypic characteristics of MR-NAS isolates from different age groups of cattle and environmental samples on preselected German dairy farms that had a history of MRSA detection.

\section{MATERIALS AND MEHODS}

\section{Sampling}

Twenty dairy herds from different regions in Germany were included in our study. Selection process and herd characteristics of the study farms were previously described (Schnitt et al., 2020). All herds were selected based on previous findings of oxacillin-resistant Staph. aureus isolates that were identified by mastitis laboratories. Because all samples were collected in the framework of a diagnostic investigation, no ethical approval was required according to the German legislation. Quarter milk samples (QMS) were collected aseptically by a trained veterinarian according to the guidelines of the German veterinary association (DVG, 2009). Teats were dry cleaned with a single-use paper towel and 3 streams were stripped in a milking cup. Teat ends were disinfected with $70 \%$ ethanol solution for approximately $15 \mathrm{~s}$, and 1 to 3 streams of milk were collected in a sterile tube (TPP AG, Trasadingen, Switzerland).

In total, 3,167 samples were collected for bacterial culture; 2,347 QMS from 597 dairy cows were included in our study, and bulk tank milk (BTM) was obtained from 19 farms. On each farm approximately 30 dairy cows were sampled. In detail, 10 high-risk cows were selected based on previous MRSA reports or current high SCC in milk. Additionally, 10 primiparous and 10 multiparous cows were randomly selected during the milking process on each farm. Nasal swabs were collected from milk-fed calves $(\mathrm{n}=203)$, postweaning calves $(\mathrm{n}=187)$, and prefresh heifers $(\mathrm{n}=191)$. Swab samples were additionally collected from the udder cleft of prefresh heifers $(\mathrm{n}=170)$. On each farm, approximately 10 milk-fed calves, 10 postweaning calves, and
10 prefresh heifers were randomly selected. On each farm, dust samples $(n=20)$ were collected by wiping barn surfaces such as walls and cubicle tubes with a boot swab. In addition, swab samples from teat liners $(\mathrm{n}=20)$ were collected. A swab sample from the suckers of automatic calf feeders was collected on 9 farms.

\section{Isolation and Molecular Characterization of MR-NAS}

Screening for MR staphylococci was performed using a double selective enrichment method, which was developed for MRSA detection (EFSA, 2007; Nemeghaire et al., 2014). The double selective enrichment method has been used for MRSA isolation from cattle before and is recommended by the European Food Safety Authority (EFSA, 2012; Nemeghaire et al., 2014). Samples were incubated in Mueller Hinton (MH) broth supplemented with $6.0 \%$ of $\mathrm{NaCl}$ for $24 \pm 2 \mathrm{~h}$ followed by a transfer of $1 \mathrm{~mL}$ of $\mathrm{MH}$ broth in $9 \mathrm{~mL}$ of tryptic soy broth supplemented with $3.5 \mathrm{mg} / \mathrm{L}$ cefoxitin and 50 $\mathrm{mg} / \mathrm{L}$ aztreonam and incubation at $37^{\circ} \mathrm{C}$ for $24 \pm 2$ h. After an internal validation process at the German National Reference Laboratory for Coagulase Positive Staphylococci, the salt concentration of the usually recommended $\mathrm{MH}$ broth was slightly reduced from $6.5 \%$ to $6.0 \%$ and the aztreonam content of the tryptic soy broth was reduced from $75 \mathrm{mg} / \mathrm{L}$ to $50 \mathrm{mg} / \mathrm{L}$ (EFSA, 2007; Tenhagen et al., 2014). The enrichment broth (50 $\mu \mathrm{L}$ ) was streaked on mannitol salt agar (MSA) containing $4 \mathrm{mg} / \mathrm{L}$ cefoxitin and incubated for $24 \pm 2 \mathrm{~h}$ at $37^{\circ} \mathrm{C}$. Each BTM sample was incubated in 3 batches of $1 \mathrm{~mL}$ of BTM and $9 \mathrm{~mL}$ of $\mathrm{MH}$ broth with $6.0 \% \mathrm{NaCl}$ for $48 \pm 2 \mathrm{~h}$ followed by transfer on MSA-cefoxitin agar. All colonies from MSA-cefoxitin plates (QMS, BTM, and swab samples) were transferred on sheep blood agar plates (Oxoid GmbH, Wesel, Germany) and incubated for $24 \pm 2 \mathrm{~h}$. Colonies from sheep blood agar plates were further analyzed by a MALDI-TOF mass spectrometer according to the manufacturer's instructions (Bruker Scientific LLC, Billerica, MA). Colonies were directly transferred on the MALDI-TOF target as previously described (Cameron et al., 2017). Colonies were further covered with $1.0 \mu \mathrm{L}$ of $\alpha$-cyano4-hydroxycinnamic acid (Bruker Scientific LLC). The reference database for species identification was provided by Bruker Scientific LLC (MBT-BDAL-8468). If phenotypically different colonies were observed on sheep blood agar plates, they were separately spotted on the MALDI-TOF target.

Further analysis included a PCR for detection of the tuf gene specific for staphylococci and the mecA gene (Kilic et al., 2010; Fosheim et al., 2011). For staphylococci that carried the mecA gene, an additional PCR for typing of the staphylococcal cassette chromosome 
mec (SCCmec) was performed (Zhang et al., 2005). A PCR for the detection of the mecC gene was performed for isolates that did not carry the mecA gene (GarcíaÁlvarez et al., 2011). Presumptive MR-NAS isolates that were not identified by MALDI-TOF but that carried the tuf gene, specific for staphylococci, were summarized as Staphylococcus spp. The NAS isolates that grew on the selective agar and carried the mecA gene were considered MR-NAS in this study. Other staphylococci growing on the selective medium but not carrying the mecA or mecC gene were named "NAS with reduced cefoxitin susceptibility" and are presented separately. Somatic cell counts in QMS were measured using a DeLaval cell counter (DeLaval International, Tumba, Sweden) according to the manufacturer's instructions.

\section{Statistical Analysis}

Positive test rate of MR-NAS and 95\% confidence interval were determined (positive test rate $=$ number of MR-NAS-positive samples/number of all samples from the specific population). The Mann-Whitney U test was used to compare the SCC in QMS affected and unaffected by MR-NAS. The SPSS multilevel binary logistic regression model was used to analyze associations between MR-NAS status and SCC, quarter position, and cow group (primiparous, multiparous, and highrisk group). Farm number was included as a hierarchical random effect. Alpha was set at 0.05. Analyses were carried out in SPSS version 26.0 (IBM Corp., Armonk, NY).

\section{RESULTS}

\section{Detection of MR-NAS in Samples from Dairy Cows}

Methicillin-resistant NAS were detected on 19/20 dairy farms included in our study (Table 1). The MRNAS positive test rate in QMS from dairy cows was 3.3\% (77/2,347; 95\% CI: 2.6-4.1\%). The MR-NAS positive test rate in QMS from randomly selected primiparous cows was $2.3 \%(15 / 657 ; 95 \%$ CI:1.3-3.7\%); in QMS from randomly selected multiparous cows the positive test rate was $4.6 \%(50 / 1,083 ; 95 \%$ CI: $3.4-6.0 \%)$, and in the high-risk group the positive test rate was $2.2 \%$ (13/603; 95\% CI: $1.2-3.7 \%)$. In $33.9 \%$ (19/56) of MRNAS-positive cows, multiple quarters were affected. On the cow level, MR-NAS were detected in $9.4 \%$ (56/597; 95\% CI: $7.2-12.0 \%$ ) of the dairy cows. In BTM, $42.1 \%$ (8/19) of samples carried MR-NAS. In 1 BTM sample, 3 different MR-NAS species were detected, whereas in the remaining positive samples only 1 species was identified.

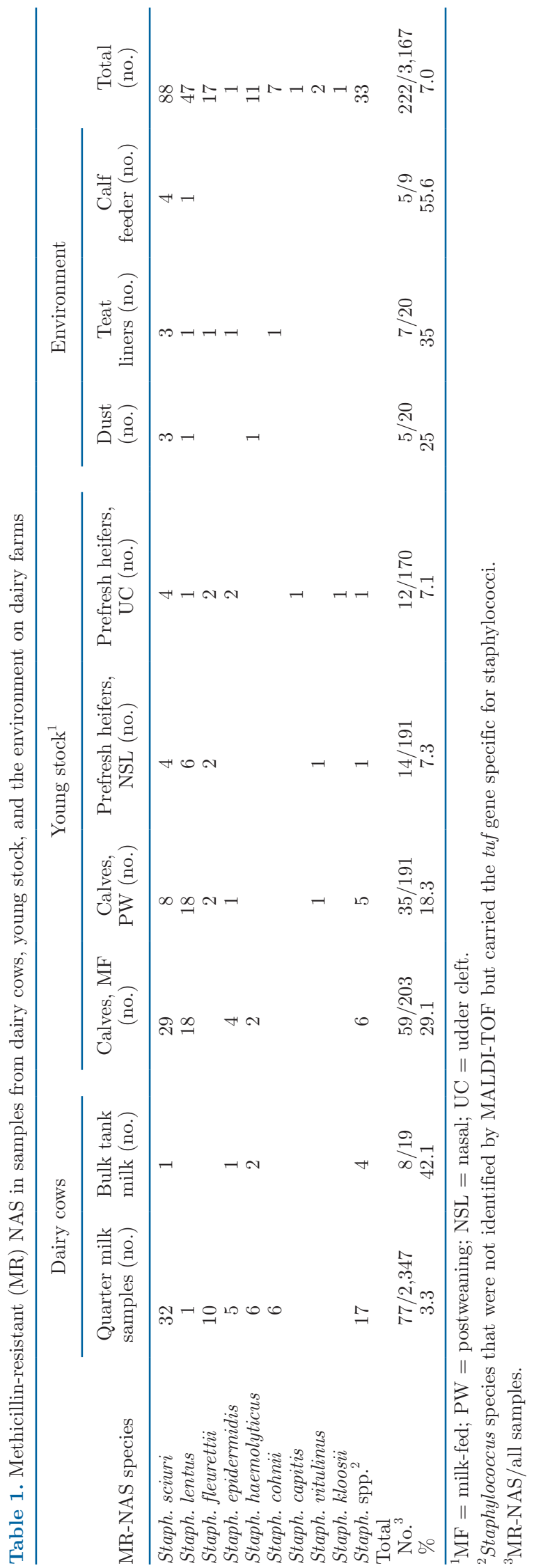


The geometric mean SCC of all QMS that carried MR-NAS was 183,000 cells $/ \mathrm{mL}$, and the geometric mean SCC of all QMS from our study was 114,000 cells/mL. Somatic cell counts were significantly higher in quarters affected by MR-NAS compared with all QMS $(P=0.001)$.

The association between MR-NAS status and cow group (primiparous, multiparous, and high risk), SCC, and affected quarter position is presented in Table 2 . High SCC was defined as $>150,000$ cells $/ \mathrm{mL}$ in primiparous cows and $>250,000$ cells $/ \mathrm{mL}$ in multiparous cows. The QMS with high SCC were approximately 1.8 times more likely to carry MR-NAS compared with QMS with low SCC (odds ratio: 1.838; 95\% CI: 1.119$3.019 ; P=0.019)$. In addition, QMS from randomly selected multiparous cows were approximately 2 times more likely to carry MR-NAS compared with QMS from randomly selected primiparous cows (odds ratio: 1.950; 95\% CI: $1.042-3.649 ; P=0.038$ ). No difference in MR-NAS positive test rate from QMS was observed between primiparous and high-risk cows or between the affected mammary quarter positions (right hind, left hind, right front, left front; Table $2 ; P>0.05$ ).

\section{Detection of MR-NAS in Samples from Young Stock and the Environment}

The MR-NAS positive test rate in nasal swab samples from milk-fed calves was 29.1\% (59/203; $95 \%$ CI: $22.0-34.8 \%$ ), and in postweaning calves the positive test rate was $18.3 \%$ (35/191; 95\% CI: $13.4-25.1 \%$; Table 1). In $12.5 \%(25 / 200 ; 95 \%$ CI: $8.3-17.9 \%)$ of all prefresh heifers, one or both samples (nasal or udder cleft swabs) carried MR-NAS. In nasal swab samples
7.3\% (14/191; 95\% CI: 4.1-12.0\%) carried MR-NAS, and $7.1 \%(12 / 170 ; 95 \%$ CI: $3.7-12.0 \%)$ of udder cleft swab samples tested positive. One prefresh heifer carried MR Staph. sciuri in the nose and in the udder cleft. Dust samples were collected from all 20 dairy farms, and MR-NAS were detected in $25 \%(5 / 20)$ of the samples. In swab samples from teat liners, MR-NAS were detected on $35.0 \%(7 / 20)$ of the farms, and suckers from automatic calf feeders tested positive on $55.6 \%$ $(5 / 9)$ of the dairy farms that used automatic feeders.

\section{MR-NAS Species}

Nine NAS species were identified by MALDI-TOF (Table 1). Staphylococcus sciuri was the most frequently detected MR-NAS species in this study $(\mathrm{n}=88)$. Staphylococcus sciuri was the only species that was detected in all sample types from this study and the most frequently detected species in QMS from dairy cows (n $=32$; Table 1). The second most common MR-NAS from QMS was Staph. fleurettii $(\mathrm{n}=10)$, followed by Staph. haemolyticus $(\mathrm{n}=6)$, Staph. cohnii $(\mathrm{n}=6)$, and Staph. epidermidis $(\mathrm{n}=5)$. In nasal swab samples from calves, Staph. sciuri $(\mathrm{n}=37)$ and Staph. lentus $(\mathrm{n}=36)$ were the most frequently detected MR-NAS species. A similar distribution was found in prefresh heifers, where Staph. sciuri $(\mathrm{n}=8)$, Staph. lentus $(\mathrm{n}=7)$, and Staph. fleurettii $(\mathrm{n}=6)$ were mostly detected. In the environment MR Staph. sciuri were isolated from dust ( $\mathrm{n}=$ 3 ), teat liners $(\mathrm{n}=3)$, and suckers from automatic calf feeders $(\mathrm{n}=4)$ from 9 farms. Staphylococcus lentus was detected in dust $(\mathrm{n}=1)$, teat liners $(\mathrm{n}=1)$, and from 1 automatic calf feeder. Additional MR-NAS species that were detected in up to 3 samples were MR Staph.

Table 2. Methicillin-resistant (MR) NAS positive test rates in quarter milk samples (QMS) and association with cow group, SCC, and quarter position

\begin{tabular}{|c|c|c|c|c|c|c|}
\hline \multirow[b]{2}{*}{ Variable } & \multirow[b]{2}{*}{ Category } & \multirow{2}{*}{$\begin{array}{l}\text { MR-NAS-positive } \\
\text { QMS }\left(\% ; \text { no. }{ }^{1}\right)\end{array}$} & \multirow{2}{*}{$\begin{array}{l}\text { Odds } \\
\text { ratio }\end{array}$} & \multicolumn{2}{|c|}{$\begin{array}{l}95 \% \text { CI of odds } \\
\text { ratio }\end{array}$} & \multirow[b]{2}{*}{$P$-value } \\
\hline & & & & Lower & Upper & \\
\hline \multirow[t]{3}{*}{ Cow group } & Primiparous & $2.3(15 / 657)$ & Referent & & & \\
\hline & Multiparous & $4.6(50 / 1,083)$ & 1.950 & 1.042 & 3.649 & 0.038 \\
\hline & High-risk $^{2}$ & $2.2(13 / 603)$ & 0.828 & 0.369 & 1.861 & 0.629 \\
\hline \multirow[t]{2}{*}{$\mathrm{SCC}^{3}$} & Low & $2.7(45 / 1,663)$ & Referent & & & \\
\hline & High & $4.9(33 / 680)$ & 1.838 & 1.119 & 3.019 & 0.019 \\
\hline \multirow[t]{4}{*}{ Quarter position } & Right hind & $3.6(21 / 588)$ & Referent & & & \\
\hline & Left hind & $4.6(27 / 588)$ & 1.326 & 0.711 & 2.471 & 0.353 \\
\hline & Right front & $2.2(13 / 584)$ & 0.651 & 0.307 & 1.379 & 0.244 \\
\hline & Left front & $2.9(17 / 587)$ & 0.840 & 0.419 & 1.683 & 0.603 \\
\hline
\end{tabular}

${ }^{1}$ No. in parentheses $=$ MR-NAS/all samples.

${ }^{2}$ Cows with previous Staph. aureus/MRSA report or recent high SCC in milk.

${ }^{3}$ Low $=<150,000$ cells $/ \mathrm{mL}$ in QMS from primiparous cows and $<250,000$ cells $/ \mathrm{mL}$ QMS from multiparous cows. High $=>150,000$ cells $/ \mathrm{mL}$ in QMS from primiparous cows and $>250,000$ cells $/ \mathrm{mL}$ QMS from multiparous cows. 
vitulinus, MR Staph. kloosii, and MR Staph. capitis (Table 1).

In addition, 170 NAS isolates were detected that grew on MSA-cefoxitin agar plates $(4 \mathrm{mg} / \mathrm{L})$ but did not harbor the mecA or mecC genes (Table 3). Because the phenotypic cut-off value for cefoxitin resistance in Staph. aureus is $4 \mathrm{mg} / \mathrm{L}$, these NAS isolates were considered to exhibit reduced cefoxitin susceptibility (CLSI, 2018). The most common NAS species with reduced cefoxitin susceptibility that carried neither the mecA gene nor the mecC gene was Staph. cohnii, which was isolated from 15/20 farms. Most Staph. cohnii were detected in milk samples $(\mathrm{n}=120)$, and the geometric mean SCC of QMS affected by Staph. cohnii was 153,000 cells/mL. From calves and prefresh heifers, 12 Staph. cohnii isolates were obtained, and 2 Staph. cohnii were isolated from dust and teat liners (Table 3). Additional NAS species with reduced cefoxitin susceptibility were Staph. pettenkoferi $(\mathrm{n}=3)$, Staph. xylosus $(\mathrm{n}=2)$, and Staph. saprophyticus $(\mathrm{n}=1)$ as well as 26 NAS that were not identified by MALDI-TOF but carried the tuf gene specific for staphylococci.

\section{MR-NAS Detection Within Farms}

The occurrence of MR-NAS species within the 20 preselected dairy farms is presented in Figure 1. The MR-NAS species that were detected fewer than 4 times in our study and isolates that were not identified by MALDI-TOF were summarized as Staphylococcus spp. in Figure 1. On farm 12, 17.1\% (21/123) of QMS carried MR Staph. sciuri and the same species was detected in samples from young stock and teat liners. On farm 4, MR Staph. sciuri was the predominant species, especially in samples of young stock but also in QMS and dust samples. On farm 10, MR Staph. lentus was most frequently detected, especially from the different calf populations. In addition, high numbers of Staph. cohnii isolates with reduced cefoxitin susceptibility (mecA/ $m e c C$ negative) were detected in QMS from farm number $1(25.5 \% ; 27 / 106)$ and number 7 (20.8\%; 25/120). On other farms (e.g., numbers 3, 5, 11, 13, and 18), up to 5 different species were detected within farms.

\section{Genotypic Characteristics of MR-NAS Isolates}

The SCCmec types of most MR-NAS (86.9\%; 193/222) were not identified. Eight Staph. haemolyticus isolates from 7 farms carried SCCmec type V. Additionally, 7 MR Staph. cohnii from 1 farm and 1 MRSE isolate from the same herd carried SCCmec type V. Eight MRSE isolates from 4 farms carried SCCmec type IVa.

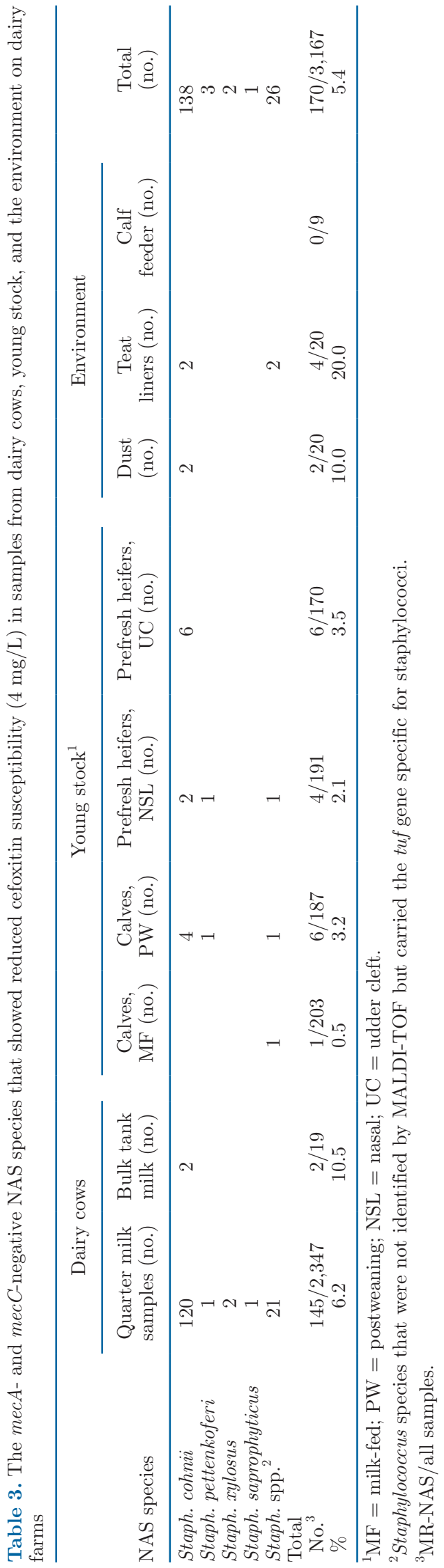




\section{DISCUSSION}

This is the first study that reports the occurrence of MR-NAS in QMS, BTM, swab samples from young stock, and the environment of dairy farms. The detection of MR-NAS from this study was based on a standardized laboratory panel for MRSA detection (EFSA, 2007; Nemeghaire et al., 2014). Cefoxitincontaining media were used for preselection of MR staphylococci. According to the European Committee of Antimicrobial Susceptibility Testing, phenotypic cefoxitin or oxacillin resistance has been recommended for mecA prediction in NAS (EUCAST, 2020). For the detection of methicillin resistance in some NAS species (Staph. pseudintermedius and Staph. schleiferi), oxacillin susceptibility was shown to be more sensitive compared with cefoxitin (Swenson and Tenover, 2005; EUCAST, 2020). Staphylococcus pseudintermedius was rarely detected in dairy cows and Staph. schleiferi was not detected in samples from cattle so far (Pilla et al., 2013). However, oxacillin and cefoxitin MIC were shown to be highly heterogeneous among NAS species. For MRSE, oxacillin MIC values between 1 and 128 mg/L were reported (Dickinson and Archer, 2000). In conclusion, NAS are a highly diverse group of bacteria, and species-specific MIC values (cefoxitin and oxacillin) are mostly unavailable and may differ from Staph. aureus- and MRSA-related MIC values. Consequently, some MR-NAS may have gone undetected using the cefoxitin-based selective enrichment procedure in this study. In addition, oxacillin-susceptible mecA-positive NAS were detected on dairy farms (Mahato et al., 2017). Oxacillin-susceptible MR-NAS would have gone undetected in this study due to the previously described enrichment method. The MR-NAS positive test rates from this study might therefore be underestimated, and comparison of MR-NAS prevalence between studies is possible only to a limited extend.

In our study, MR-NAS were detected in $3.3 \%$ (77/2,347; 95\% CI: $2.6-4.1 \%)$ of the QMS from preselected dairy herds. A study from Switzerland reported 55 MR-NAS isolated from 370 QMS, which is a higher proportion compared with our results (Frey et al., 2013). However, all isolates from the Swiss study were obtained from mastitis milk samples, and the authors mentioned that from multiple samples more than 1 NAS species was isolated. Therefore, the MR-NAS prevalence was probably overestimated. Low numbers of mecA geneharboring isolates among NAS isolates from different cows were detected in Canada $(0.9 \%$ (4/405; Nobrega

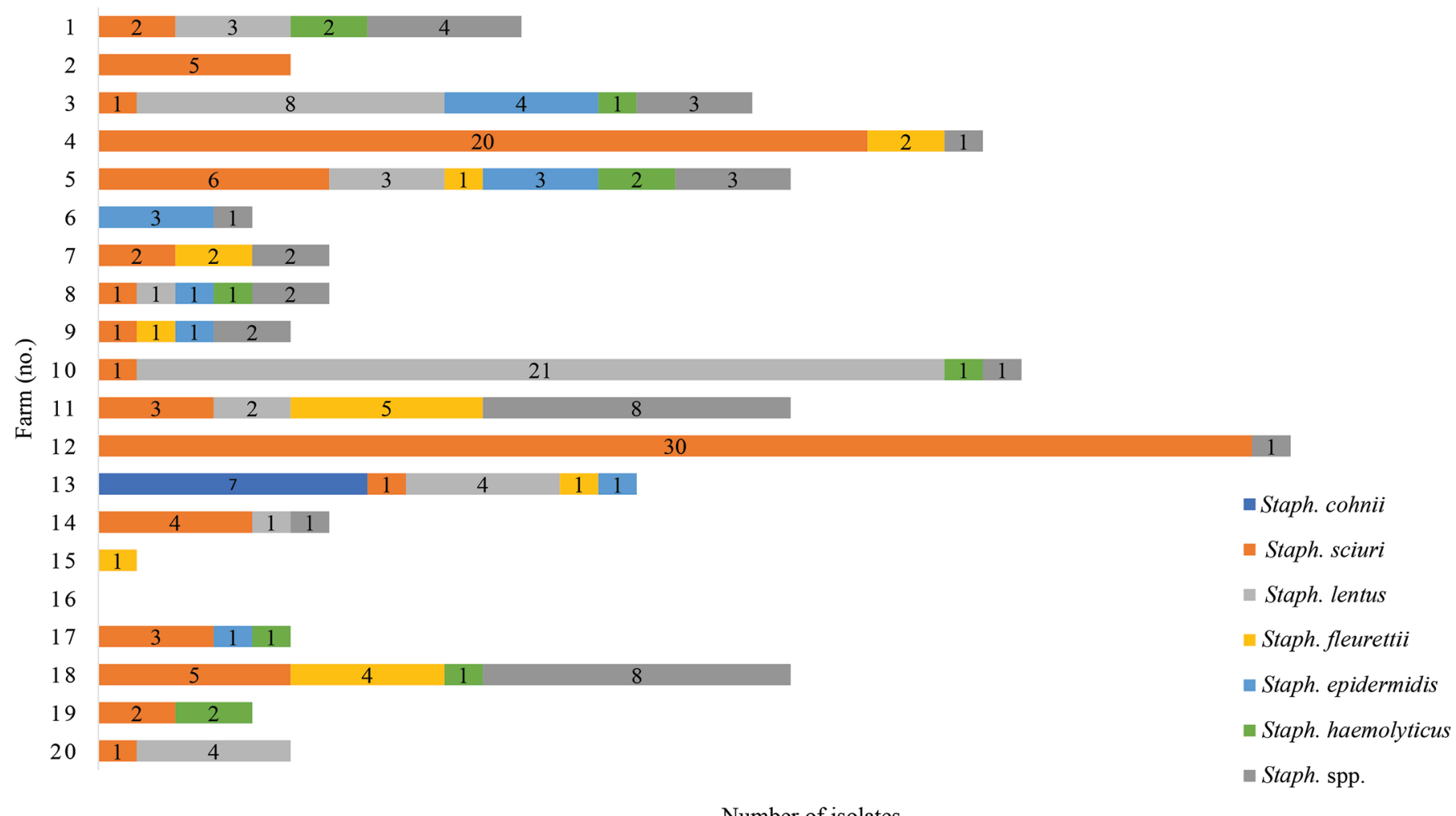

Number of isolates

Figure 1. Methicillin-resistant NAS in samples from dairy cows, young stock, and the environment of 20 preselected dairy farms. 
et al., 2018). In studies that investigated methicillin resistance of NAS from mastitis milk samples, prevalence ranged from $14.1 \%(26 / 170)$ in the Netherlands up to $73.2 \%(82 / 112)$ in a study from China (Sampimon et al., 2011; Qu et al., 2019). In our study, MR-NAS were isolated from $42.1 \%(8 / 19)$ of BTM samples of preselected herds. A study from Switzerland reported that $62 \%(62 / 100)$ of BTM samples carried MR-NAS, which is a higher proportion compared with our study (Huber et al., 2011). In the United States, 1 study reported 11 MR-NAS isolates in BTM samples from 7/288 farms (2.4\%; Cicconi-Hogan et al., 2014). In the United Kingdom, $4.1 \%(15 / 363)$ of BTM samples carried MR-NAS (Fisher and Paterson, 2020).

In this study, randomly selected multiparous cows were more likely to carry MR-NAS in QMS compared with primiparous cows (odds ratio: 1.950; 95\% CI: $1.042-3.649 ; P=0.038$ ). Previous studies that did not investigate methicillin resistance reported a higher NAS prevalence in primiparous cows (De Visscher et al., 2016; Condas et al., 2017). In a Canadian study, primiparous cows were 3 times more likely to carry Staph. chromogenes compared with multiparous cows (Condas et al., 2017). Therefore, the absence of this species in our study may explain the higher MR-NAS positive test rate in multiparous cows. Cows from the high-risk group were not more likely to carry MR-NAS than randomly selected primiparous and multiparous cows $(P=$ 0.629). This can be explained by the definition of the high-risk group, which was focused on previous MRSA reports and not on MR-NAS detection. No difference in MR-NAS positive test rate between quarters (right hind, left hind, right front, left front) was observed in our study. Similarly, no significant differences in NAS prevalence between quarter positions was reported from previous studies that did not perform resistance testing (De Visscher et al., 2016; Condas et al., 2017).

The MR-NAS positive test rate among calves in our study was $29.1 \%$ (59/203; 95\% CI: $22.0-34.8 \%$ ) in milkfed calves and $18.3 \%(35 / 191 ; 95 \%$ CI: $13.4-25.1 \%)$ in postweaning calves. A study from Belgium reported an MR-NAS carriage rate in dairy calves of $13.1 \%$, which is lower compared with our study (Vanderhaeghen et al., 2013). In Switzerland, 62\% (62/100) of nasal swabs from calves carried MR-NAS, which is a higher detection rate compared with our study (Huber et al., 2011). However, the authors of the Swiss study did not report whether dairy calves, veal calves, or beef calves were sampled.

Most studies that investigated methicillin resistance in NAS from milk samples reported MR Staph. sciuri (Frey et al., 2013; Mahato et al., 2017; Fisher and Paterson, 2020) and MRSE (Taponen et al., 2015; Nobrega et al., 2018; Kim et al., 2019) as the most frequently detected MR-NAS species. Methicillin-resistant Staph. sciuri was the most common MR-NAS species in our study as well. Methicillin-resistant Staph. epidermidis was detected in 5 QMS from 3 farms. In particular, MRSE was shown to exhibit low phenotypic oxacillin resistance in some cases (Mahato et al., 2017; Dickinson and Archer, 2000). Therefore, low MRSE detection rates in this study might be caused by the cefoxitinbased selection procedure in this study. The second most common MR-NAS species from QMS in our study was MR Staph. fleurettii, which was the most frequently detected MR-NAS species in BTM from Switzerland (Huber et al., 2011). In addition, we detected high numbers of Staph. cohnii $(\mathrm{n}=120)$ that showed reduced cefoxitin susceptibility but did not carry the mecA or mecC gene. In previous studies, MR Staph. cohnii and phenotypically oxacillin-resistant Staph. cohnii were rarely detected (Huber et al., 2011; Frey et al., 2013). Studies that did not investigate methicillin resistance suggested that Staph. cohnii should be regarded as an environmental commensal NAS species on dairy farms (De Visscher et al., 2016; Wuytack et al., 2020b). In a Danish study, Staph. cohnii was one of the most common NAS species isolated from teat skin swabs (Mahmmod et al., 2018). We detected Staph. cohnii mostly in QMS, with up to $25.5 \%$ positive samples within farms. Although we performed aseptic milk sampling procedures, it cannot be excluded that some Staph. cohnii in QMS from our study occurred from teat-end contamination. In the field, a clean collection of QMS is sometimes difficult, especially if cows and milking parlors are dirty and time for teat cleaning is limited during the milking process. A high detection rate of Staph. cohnii isolates with reduced cefoxitin susceptibility in QMS and a slightly higher geometric mean SCC in Staph. cohnii affected quarters compared with the cell count of all QMS from this study $(153,000$ cells $/ \mathrm{mL}$ vs. 114,000 cells $/ \mathrm{mL}$ ) indicate that Staph. cohnii could act as a cow-associated opportunistic mastitis pathogen. Because our detection method was focused on MR staphylococci, the role of other mastitis pathogens as a cause of elevated SCC remains unclear. Staphylococcus chromogenes, which is the most frequently detected mastitis-causing NAS pathogen worldwide, was not detected in our study, in which only presumably MRNAS were analyzed. Previous studies reported that Staph. chromogenes harbors low numbers of resistance genes, and MR Staph. chromogenes was rarely detected in samples from dairy cows (Cicconi-Hogan et al., 2014; Nobrega et al., 2018; Wuytack et al., 2020a). Missing Staph. chromogenes isolates from dairy cows in this study is therefore probably caused by the cefoxitin selection criterion. It remains unclear why Staph. chromogenes is the predominant NAS species isolated from mastitis 
milk samples worldwide. Broad-spectrum $\beta$-lactam resistance is probably not the driver for natural selection of Staph. chromogenes as a mastitis-causing pathogen.

The detection of predominant MR-NAS species within dairy farms suggests a possible contagious transmission (Figure 1). On farm number 12, MR Staph. sciuri $(\mathrm{n}=21)$ was the only species isolated from QMS and additionally in samples from teat liners and young stock. Similarly, predominant species were detected on farms number 4 (Staph. sciuri) and number 10 (Staph. lentus). Contagious transmission may have also occurred on farms numbers 1 and 7, where high numbers of Staph. cohnii isolates were detected in QMS $(\mathrm{n}=25$ and 27, respectively). The Staph. cohnii isolates showed a reduced susceptibility to cefoxitin but did not carry the mecA or mecC gene and were therefore not considered MR-NAS and not included in Figure 1. On most of the remaining farms (e.g., numbers $1,3,5,11,13$, and 18), multiple different MR-NAS species were detected. Therefore, a contagious transmission of MR-NAS seems unlikely within these farms.

The most common MR-NAS species from calves in our study were MR Staph. sciuri and MR Staph. lentus. In a study from Belgium, MR Staph. lentus was not detected in swab samples from dairy calves, but it was the most common MR-NAS species in nasal swabs from veal calves (Vanderhaeghen et al., 2013). The most common MR-NAS species from environmental samples in our study were MR Staph. sciuri $(\mathrm{n}=10)$ and MR Staph. lentus $(\mathrm{n}=3)$. To date, no studies were performed that investigated methicillin resistance in NAS from the environment of dairy farms. In dust samples from pig barns, MR Staph. sciuri has been isolated before (Tulinski et al., 2012). In studies that did not include resistance testing, Staph. sciuri was frequently isolated from environmental samples, which is in line with our results (Piessens et al., 2011; De Visscher et al., 2014). Additional environmental NAS species on dairy farms from different studies were Staph. fleurettii, Staph. equorum, and Staph. haemolyticus (De Visscher et al., 2014; Jenkins et al., 2019). In our study, MR Staph. haemolyticus was detected in only 1 dust sample and MR Staph. fleurettii in teat liners from 1 farm.

In the framework of our field study, we recently reported the occurrence of MRSA in the 20 preselected study farms (Schnitt et al., 2020). In BTM, the proportion of MRSA-positive samples $(63.2 \% ; 12 / 19)$ was slightly higher than the proportion of MR-NAS-positive BTM samples $(42.1 \% ; 8 / 19)$. Except for BTM, the MR-NAS positive test rate was similar or higher in all sample types compared with the MRSA positive test rate from our study. The MRSA positive test rate in QMS from preselected cows was $2.9 \%(67 / 2,347)$, and the MRNAS positive test rate was $3.3 \%(77 / 2,347$; Schnitt et al., 2020). In addition, some MR-NAS species might have gone undetected in this study due to the cefoxitinbased selection procedure. This indicates that on dairy farms with an MRSA history, MR-NAS are equally or more prevalent than MRSA. This is not surprising because the classification of Staph. aureus and NAS is based on their pathogenic potential, and NAS consist of various staphylococcal species compared with Staph. aureus as a single pathogen. The effect of MRSA on the SCC in QMS (geometric mean: 345,000 cells/mL) was higher compared with MR-NAS-affected quarters (geometric mean: 183,000 cells/mL). This finding underlines the role of NAS (MR-NAS) as mastitis-causing pathogens of minor importance compared with Staph. aureus (MRSA).

The resistance mechanisms and related genes that mediate reduced cefoxitin susceptibility in the NAS species from Table 3 that did not carry the mecA or $m e c C$ gene remain unknown. The genetic background of cefoxitin and methicillin resistance in NAS is more diverse compared with Staph. aureus, and expression of the mecA gene is heterogeneous across NAS species (Becker et al., 2014; Humphries et al., 2020). Therefore, mecA- and mecC-negative NAS that exhibit reduced susceptibility to cefoxitin and oxacillin should be further investigated for genotypic resistance mechanisms. Previous studies reported a hyperproduction of $\beta$-lactamase (Argudín et al., 2018; Scholtzek et al., 2019) and different modifications in the penicillinbinding protein as a cause of broad-spectrum $\beta$-lactam resistance in Staph. aureus (Chambers, 1997).

The role of MR-NAS as a potential reservoir of resistance genes that may be transferred to methicillinsensitive Staph. aureus has been discussed in numerous studies, and relatively little is known about the underlying mechanisms in vivo (Haaber et al., 2016; Miragaia, 2018; Fisher and Paterson, 2020). In the laboratory, transfer of SCCmec elements has been achieved by conjugation (plasmids), transduction (phages), and transformation (DNA uptake from the environment; Morikawa et al., 2012; Chlebowicz et al., 2014; Ray et al., 2016). In samples from 6 farms in our study, MR Staph. haemolyticus were detected that carried the same SCCmec type (V) as the MRSA on these farms. On one more farm, SCCmec type V was detected in MR Staph. cohnii, MRSE, and MRSA. It might be hypothesized that SCCmec elements have been transmitted from methicillin-resistant to susceptible staphylococcal species on these farms, leading to a higher number of resistant strains. To further investigate the similarity between the SCCmec elements and thus give hints for transmission events, in-depth analyses of the SCCmec DNA sequences should be performed. Because the majority of SCCmec types in MR-NAS $(86.9 \% ; 193 / 222)$ 
could not be characterized in our study, whereas most MRSA strains carried SCCmec type V, a recent transmission of SCCmec elements seems unlikely (Schnitt et al., 2020). Different SCCmec types in NAS and Staph. aureus from dairy farms were previously reported (Vanderhaeghen et al., 2013). However, a possible transfer of the mec gene complex, independent of the SCCmec cassette, was also described in NAS from BTM of dairy farms (Fisher and Paterson, 2020).

\section{CONCLUSIONS}

Methicillin-resistant NAS were detected in different age groups of cattle and in the environment of 20 dairy farms that were preselected based on previous MRSA findings. The most frequently detected MR-NAS species from dairy farms was MR Staph. sciuri; MR Staph. lentus was the second most common species, especially in samples from calves. Additional MR-NAS species that were repeatedly detected in our study were Staph. fleurettii, Staph. epidermidis, and Staph. haemolyticus. On 15/20 farms, high numbers of Staph. cohnii ( $\mathrm{n}=$ 120) were detected in QMS that showed a reduced susceptibility to cefoxitin but did not carry the mecA or $m e c C$ genes. The QMS with high SCC were more likely to carry MR-NAS compared with all QMS included in our study, indicating a small but significant effect of MR-NAS on udder health. The MR-NAS positive test rate in samples from dairy farms was higher compared with the MRSA positive test rate from our study. This is important because resistance genes can be transferred between MR-NAS and the major mastitis pathogen Staph. aureus.

\section{ACKNOWLEDGMENTS}

This study was carried out in the framework of the project \#1HealthPREVENT, funded by the German Federal Ministry of Education and Research (Bonn, Germany), grant no. 01KI1727C. We thank all farmers who voluntarily participated in the study. We also thank Ulrike Sorge (Tiergesundheitsdienst Bayern e.V., Poing, Germany), Thomas Peters (MBFG mbH, Wunsdorf, Germany), Karsten Donat (Thüringer Tierseuchenkasse, Jena, Germany), Sabine Reinhold (Tierärztliche Praxis am Weinberg, Jessen, Germany), Oliver Claushues (Landeskontrollverband NordrheinWestfalen e.V., Krefeld, Germany), Karin Eulenberger (Sächsische Tierseuchenkasse, Dresden, Germany), and Natalie Morgenstern (Landesuntersuchungsanstalt Sachsen, Dresden, Germany) for supporting the identification of study farms. The authors declare no conflicts of interest.

\section{REFERENCES}

Argudín, M. A., S. Roisin, L. Nienhaus, M. Dodémont, R. de Mendonça, C. Nonhoff, A. Deplano, and O. Denis. 2018. Genetic diversity among Staphylococcus aureus isolates showing oxacillin and/ or cefoxitin resistance not linked to the presence of mec genes. Antimicrob. Agents Chemother. 62:e00091-18. https://doi.org/10 .1128/AAC.00091-18.

Becker, K., B. Ballhausen, R. Kock, and A. Kriegeskorte. 2014. Methicillin resistance in Staphylococcus isolates: The "mec alphabet" with specific consideration of mecC, a mec homolog associated with zoonotic S. aureus lineages. Int. J. Med. Microbiol. 304:794804. https://doi.org/10.1016/j.ijmm.2014.06.007.

Becker, K., A. Both, S. Weißelberg, C. Heilmann, and H. Rohde. 2020. Emergence of coagulase-negative staphylococci. Expert Rev. Anti Infect. Ther. 18:349-366. https://doi.org/10.1080/14787210.2020 .1730813 .

Cameron, M., H. W. Barkema, J. De Buck, S. De Vliegher, M. Chaffer, J. Lewis, and G. P. Keefe. 2017. Identification of bovine-associated coagulase-negative staphylococci by matrix-assisted laser desorption/ionization time-of-flight mass spectrometry using a direct transfer protocol. J. Dairy Sci. 100:2137-2147. https://doi.org/10 .3168/jds.2016-12020.

Chambers, H. F. 1997. Methicillin resistance in staphylococci: Molecular and biochemical basis and clinical implications. Clin. Microbiol. Rev. 10:781-791. https://doi.org/10.1128/CMR.10.4.781.

Chlebowicz, M. A., I. Maslanova, L. Kuntova, H. Grundmann, R. Pantucek, J. Doskar, J. M. van Dijl, and G. Buist. 2014. The staphylococcal cassette chromosome mec type V from Staphylococcus aureus ST398 is packaged into bacteriophage capsids. Int J. Med. Microbiol. 304:764-774. https://doi.org/10.1016/j.ijmm .2014.05.010.

Cicconi-Hogan, K. M., N. Belomestnykh, M. Gamroth, P. L. Ruegg, L. Tikofsky, and Y. H. Schukken. 2014. Short communication: Prevalence of methicillin resistance in coagulase-negative staphylococci and Staphylococcus aureus isolated from bulk milk on organic and conventional dairy farms in the United States. J. Dairy Sci. 97:2959-2964. https://doi.org/10.3168/jds.2013-7523.

CLSI (Clinical and Laboratory Standards Institute). 2018. M100: Performance Standards for Antimicrobial Susceptibility Testing. 28th ed. CLSI, Wayne, PA.

Condas, L. A. Z., J. De Buck, D. B. Nobrega, D. A. Carson, S. Naushad, S. De Vliegher, R. N. Zadoks, J. R. Middleton, S. Dufour, J. P. Kastelic, and H. W. Barkema. 2017. Prevalence of non-aureus staphylococci species causing intramammary infections in Canadian dairy herds. J. Dairy Sci. 100:5592-5612. https://doi.org/10 .3168/jds.2016-12478.

De Visscher, A., S. Piepers, F. Haesebrouck, and S. De Vliegher. 2016. Intramammary infection with coagulase-negative staphylococci at parturition: Species-specific prevalence, risk factors, and effect on udder health. J. Dairy Sci. 99:6457-6469. https://doi.org/10.3168/ jds.2015-10458.

De Visscher, A., S. Piepers, F. Haesebrouck, K. Supré, and S. De Vliegher. 2017. Coagulase-negative Staphylococcus species in bulk milk: Prevalence, distribution, and associated subgroup- and species-specific risk factors. J. Dairy Sci. 100:629-642. https://doi .org/10.3168/jds.2016-11476.

De Visscher, A., K. Supré, F. Haesebrouck, R. N. Zadoks, V. Piessens, E. Van Coillie, S. Piepers, and S. De Vliegher. 2014. Further evidence for the existence of environmental and host-associated species of coagulase-negative staphylococci in dairy cattle. Vet. Microbiol. 172:466-474. https://doi.org/10.1016/j.vetmic.2014.06 .011 .

Dickinson, T. M., and G. L. Archer. 2000. Phenotypic expression of oxacillin resistance in Staphylococcus epidermidis: Roles of mecA transcriptional regulation and resistant-subpopulation selection. Antimicrob. Agents Chemother. 44:1616-1623. https://doi.org/10 $.1128 /$ AAC.44.6.1616-1623.2000.

DVG. 2009. Leitlinien Entnahme von Milchproben unter antiseptischen Bedingungen und Isolierung und Identifizierung von Mastitis 
Erregern. 2nd ed. Verlag der Deutschen Veterinärmedizinischen Gesellschaft, Gießen, Germany.

EFSA. 2007. Report of the Task Force on Zoonoses Data Collection on a proposal for technical specifications for a baseline survey on the prevalence of methicillin resistant Staphylococcus aureus (MRSA) in breeding pigs. EFSA J. 129:1-14.

EFSA. 2012. Technical specifications on the harmonised monitoring and reporting of antimicrobial resistance in methicillin-resistant Staphylococcus aureus in food-producing animals and food. EFSA J. 10:2897. https://doi.org/10.2903/j.efsa.2012.2897.

EUCAST (European Committee on Antimicrobial Susceptibility Testing). 2020. Breakpoint tables for interpretation of MICs and zone diameters. Version 10.0. Accessed Dec. 2020. https://www.eucast .org/clinical_breakpoints/.

Fisher, E. A., and G. K. Paterson. 2020. Prevalence and characterisation of methicillin-resistant staphylococci from bovine bulk tank milk in England and Wales. J. Glob. Antimicrob. Resist. 22:139144. https://doi.org/10.1016/j.jgar.2020.01.013.

Fosheim, G. E., A. C. Nicholson, V. S. Albrecht, and B. M. Limbago. 2011. Multiplex real-time PCR assay for detection of methicillinresistant Staphylococcus aureus and associated toxin genes. J. Clin. Microbiol. 49:3071-3073. https://doi.org/10.1128/JCM.00795-11.

Frey, Y., J. P. Rodriguez, A. Thomann, S. Schwendener, and V. Perreten. 2013. Genetic characterization of antimicrobial resistance in coagulase-negative staphylococci from bovine mastitis milk. J. Dairy Sci. 96:2247-2257. https://doi.org/10.3168/jds.2012-6091.

García-Alvarez, L., M. T. G. Holden, H. Lindsay, C. R. Webb, D. F. J. Brown, M. D. Curran, E. Walpole, K. Brooks, D. J. Pickard, C. Teale, J. Parkhill, S. D. Bentley, G. F. Edwards, E. K. Girvan, A. M. Kearns, B. Pichon, R. L. R. Hill, A. R. Larsen, R. L. Skov, S. J. Peacock, D. J. Maskell, and M. A. Holmes. 2011. Methicillinresistant Staphylococcus aureus with a novel mecA homologue in human and bovine populations in the UK and Denmark: A descriptive study. Lancet Infect. Dis. 11:595-603. https://doi.org/10 .1016/S1473-3099(11)70126-8.

Gindonis, V., S. Taponen, A. L. Myllyniemi, S. Pyörälä, S. Nykäsenoja, S. Salmenlinna, L. Lindholm, and M. Rantala. 2013. Occurrence and characterization of methicillin-resistant staphylococci from bovine mastitis milk samples in Finland. Acta Vet. Scand. 55:61. https://doi.org/10.1186/1751-0147-55-61.

Haaber, J., J. J. Leisner, M. T. Cohn, A. Catalan-Moreno, J. B. Nielsen, H. Westh, J. R. Penadés, and H. Ingmer. 2016. Bacterial viruses enable their host to acquire antibiotic resistance genes from neighbouring cells. Nat. Commun. 7:13333. https://doi.org/ 10.1038/ncomms13333.

Huber, H., D. Ziegler, V. Pflüger, G. Vogel, C. Zweifel, and R. Stephan. 2011. Prevalence and characteristics of methicillin-resistant coagulase-negative staphylococci from livestock, chicken carcasses, bulk tank milk, minced meat, and contact persons. BMC Vet. Res. 7:6. https://doi.org/10.1186/1746-6148-7-6.

Humphries, R. M., P. Magnano, C. A. Burnham, J. Dien Bard, T. C. Dingle, K. Callan, and L. F. Westblade. 2020. Evaluation of surrogate tests for the presence of mecA-mediated methicillin resistance in Staphylococcus haemolyticus, Staphylococcus hominis, Staphylococcus capitis and Staphylococcus warneri. J. Clin. Microbiol. JCM.02290-20. https://doi.org/10.1128/JCM.02290-20.

Jenkins, S. N., E. Okello, P. V. Rossitto, T. W. Lehenbauer, J. Champagne, M. C. T. Penedo, A. G. Arruda, S. Godden, P. Rapnicki, P. J. Gorden, L. L. Timms, and S. S. Aly. 2019. Molecular epidemiology of coagulase-negative Staphylococcus species isolated at different lactation stages from dairy cattle in the United States. PeerJ 7:e6749. https://doi.org/10.7717/peerj.6749.

Kilic, A., K. L. Muldrew, Y. W. Tang, and A. C. Basustaoglu. 2010. Triplex real-time polymerase chain reaction assay for simultaneous detection of Staphylococcus aureus and coagulase-negative staphylococci and determination of methicillin resistance directly from positive blood culture bottles. Diagn. Microbiol. Infect. Dis. 66:349-355. https://doi.org/10.1016/j.diagmicrobio.2009.11.010.

Kim, S. J., D. C. Moon, S. C. Park, H. Y. Kang, S. H. Na, and S. K. Lim. 2019. Antimicrobial resistance and genetic characterization of coagulase-negative staphylococci from bovine mastitis milk samples in Korea. J. Dairy Sci. 102:11439-11448. https://doi.org/ $10.3168 /$ jds.2019-17028.

Mahato, S., H. U. Mistry, S. Chakraborty, P. Sharma, R. Saravanan, and V. Bhandari. 2017. Identification of variable traits among the methicillin resistant and sensitive coagulase negative staphylococci in milk samples from mastitic cows in India. Front. Microbiol. 8:1446. https://doi.org/10.3389/fmicb.2017.01446.

Mahmmod, Y. S., I. C. Klaas, L. Svennesen, K. Pedersen, and H. Ingmer. 2018. Communications of Staphylococcus aureus and non-aureus Staphylococcus species from bovine intramammary infections and teat apex colonization. J. Dairy Sci. 101:7322-7333. https:// doi.org/10.3168/jds.2017-14311.

Miragaia, M. 2018. Factors contributing to the evolution of mecAmediated $\beta$-lactam resistance in staphylococci: Update and new insights from whole genome sequencing (WGS). Front. Microbiol. 9:2723. https://doi.org/10.3389/fmicb.2018.02723.

Morikawa, K., A. J. Takemura, Y. Inose, M. Tsai, L. T. Nguyen Thi, T. Ohta, and T. Msadek. 2012. Expression of a cryptic secondary sigma factor gene unveils natural competence for DNA transformation in Staphylococcus aureus. PLoS Pathog. 8:e1003003. https:// doi.org/10.1371/journal.ppat.1003003.

Nemeghaire, S., M. A. Argudin, F. Haesebrouck, and P. Butaye. 2014 Epidemiology and molecular characterization of methicillin-resistant Staphylococcus aureus nasal carriage isolates from bovines. BMC Vet. Res. 10:153. https://doi.org/10.1186/1746-6148-10-153.

Nobrega, D. B., S. Naushad, S. A. Naqvi, L. A. Z. Condas, V. Saini, J. P. Kastelic, C. Luby, J. De Buck, and H. W. Barkema. 2018. Prevalence and genetic basis of antimicrobial resistance in nonaureus staphylococci isolated from Canadian dairy herds. Front. Microbiol. 9:256. https://doi.org/10.3389/fmicb.2018.00256.

Piessens, V., E. Van Coillie, B. Verbist, K. Supré, G. Braem, A. Van Nuffel, L. De Vuyst, M. Heyndrickx, and S. De Vliegher. 2011. Distribution of coagulase-negative Staphylococcus species from milk and environment of dairy cows differs between herds. J. Dairy Sci. 94:2933-2944. https://doi.org/10.3168/jds.2010-3956.

Pilla, R., C. Bonura, M. Malvisi, G. G. M. Snel, and R. Piccinini. 2013. Methicillin-resistant Staphylococcus pseudintermedius as a causative agent of dairy cow mastitis. Vet. Rec. 173:19.

Qu, Y., H. Zhao, D. B. Nobrega, E. R. Cobo, B. Han, Z. Zhao, S. Li, M. Li, H. W. Barkema, and J. Gao. 2019. Molecular epidemiology and distribution of antimicrobial resistance genes of Staphylococcus species isolated from Chinese dairy cows with clinical mastitis. J. Dairy Sci. 102:1571-1583. https://doi.org/10.3168/jds.2018-15136.

Ray, M. D., S. Boundy, and G. L. Archer. 2016. Transfer of the methicillin resistance genomic island among staphylococci by conjugation. Mol. Microbiol. 100:675-685. https://doi.org/10.1111/mmi .13340 .

Ruegg, P. L. 2018. Making antibiotic treatment decisions for clinical mastitis. Vet. Clin. North Am. Food Anim. Pract. 34:413-425. https://doi.org/10.1016/j.cvfa.2018.06.002.

Sampimon, O. C., T. J. Lam, D. J. Mevius, Y. H. Schukken, and R. N. Zadoks. 2011. Antimicrobial susceptibility of coagulase-negative staphylococci isolated from bovine milk samples. Vet. Microbiol. 150:173-179. https://doi.org/10.1016/j.vetmic.2011.01.017.

Schnitt, A., T. Lienen, H. Wichmann-Schauer, C. Cuny, and B.-A. Tenhagen. 2020. The occurrence and distribution of livestock-associated methicillin-resistant Staphylococcus aureus ST398 on German dairy farms. J. Dairy Sci. 103:11806-11819. https://doi.org/ 10.3168/jds.2020-18958.

Scholtzek, A. D., D. Hanke, B. Walther, I. Eichhorn, S. D. Stöckle, K. S. Klein, H. Gehlen, A. Lübke-Becker, S. Schwarz, and A. T. Feßler. 2019. Molecular characterization of equine Staphylococcus aureus isolates exhibiting reduced oxacillin susceptibility. Toxins (Basel) 11:535. https://doi.org/10.3390/toxins11090535.

Schukken, Y. H., R. N. González, L. L. Tikofsky, H. F. Schulte, C. G. Santisteban, F. L. Welcome, G. J. Bennett, M. J. Zurakowski, and R. N. Zadoks. 2009. CNS mastitis: Nothing to worry about? Vet. Microbiol. 134:9-14. https://doi.org/10.1016/j.vetmic.2008 .09 .014 .

Seixas, R., J. P. Santos, R. Bexiga, C. L. Vilela, and M. Oliveira. 2014. Short communication: Antimicrobial resistance and virulence 
characterization of methicillin-resistant staphylococci isolates from bovine mastitis cases in Portugal. J. Dairy Sci. 97:340-344. https: //doi.org/10.3168/jds.2013-7130.

Supré, K., F. Haesebrouck, R. N. Zadoks, M. Vaneechoutte, S. Piepers, and S. De Vliegher. 2011. Some coagulase-negative Staphylococcus species affect udder health more than others. J. Dairy Sci. 94:2329-2340. https://doi.org/10.3168/jds.2010-3741.

Swenson, J. M., and F. C. Tenover. 2005. Results of disk diffusion testing with cefoxitin correlate with presence of mecA in Staphylococcus spp. J. Clin. Microbiol. 43:3818-3823. https://doi.org/10 .1128/JCM.43.8.3818-3823.2005.

Taponen, S., S. Nykäsenoja, T. Pohjanvirta, A. Pitkälä, and S. Pyörälä. 2015. Species distribution and in vitro antimicrobial susceptibility of coagulase-negative staphylococci isolated from bovine mastitic milk. Acta Vet. Scand. 58:12. https://doi.org/10.1186/s13028-016 -0193-8.

Tenhagen, B. A., B. Vossenkuhl, A. Kasbohrer, K. Alt, B. Kraushaar, B. Guerra, A. Schroeter, and A. Fetsch. 2014. Methicillinresistant Staphylococcus aureus in cattle food chains - Prevalence, diversity, and antimicrobial resistance in Germany. J. Anim. Sci. 92:2741-2751.

Tulinski, P., A. C. Fluit, J. A. Wagenaar, D. Mevius, L. van de Vijver, and B. Duim. 2012. Methicillin-resistant coagulase-negative staphylococci on pig farms as a reservoir of heterogeneous staphylococcal cassette chromosome mec elements. Appl. Environ. Microbiol. 78:299-304. https://doi.org/10.1128/AEM.05594-11.

Vanderhaeghen, W., S. Piepers, F. Leroy, E. Van Coillie, F. Haesebrouck, and S. De Vliegher. 2015. Identification, typing, ecology and epidemiology of coagulase negative staphylococci associated with ruminants. Vet. J. 203:44-51. https://doi.org/10.1016/j.tvjl 2014.11.001.
Vanderhaeghen, W., S. Vandendriessche, F. Crombé, S. Nemeghaire, M. Dispas, O. Denis, K. Hermans, F. Haesebrouck, and P. Butaye. 2013. Characterization of methicillin-resistant non-Staphylococcus aureus staphylococci carriage isolates from different bovine populations. J. Antimicrob. Chemother. 68:300-307. https://doi.org/10 $.1093 / \mathrm{jac} / \mathrm{dks} 403$.

Wuytack, A., A. De Visscher, S. Piepers, F. Boyen, F. Haesebrouck, and S. De Vliegher. 2020a. Distribution of non-aureus staphylococci from quarter milk, teat apices and rectal feces of dairy cows, and their virulence potential. J. Dairy Sci. 103:10658-10675. https: //doi.org/10.3168/jds.2020-18265.

Wuytack, A., A. De Visscher, S. Piepers, F. Haesebrouck, and S. De Vliegher. 2020b. Fecal non-aureus staphylococci are a potential cause of bovine intramammary infection. Vet. Res. 51:32. https:// doi.org/10.1186/s13567-020-00761-5.

Zhang, K., J. A. McClure, S. Elsayed, T. Louie, and J. M. Conly. 2005. Novel multiplex PCR assay for characterization and concomitant subtyping of staphylococcal cassette chromosome mec types I to V in methicillin-resistant Staphylococcus aureus. J. Clin. Microbiol. 43:5026-5033. https://doi.org/10.1128/JCM.43.10.5026-5033 .2005 .

\section{ORCIDS}

A. Schnitt @ https://orcid.org/0000-0003-0396-6583

T. Lienen (๑) https://orcid.org/0000-0003-2564-1472

H. Wichmann-Schauer @ https://orcid.org/0000-0001-8419-3994

B.-A. Tenhagen $\odot$ https://orcid.org/0000-0002-2191-7569 